\title{
Intracellular Developmental Timers
}

\author{
M. RAFF \\ MRC Laboratory for Molecular Cell Biology and the Biology Department, \\ University College London, London WC1E 6BT, United Kingdom
}

\begin{abstract}
One of the most poorly understood aspects of animal development is how the timing of developmental events is controlled. In most vertebrate cell lineages, for example, precursor cells divide a limited number of times before they stop and terminally differentiate, but it is not known what controls when the cells stop dividing and differentiate. There is increasing evidence, however, that intracellular timers play an important part. Such cell-intrinsic timers are examples of intracellular developmental programs that change precursor cells over time. My colleagues and I have studied such intracellular timers and programs in rodent oligodendrocyte precursor cells (OPCs), as reviewed here.
\end{abstract}

\section{INTRODUCTION}

Our interest in developmental timing began with a surprising experimental result obtained by Erika Abney, an immunologist who joined our group in the late 1970s. We had earlier defined a set of cell-type-specific markers that allowed us to distinguish the major types of glial cells found in suspensions and cultures of rat central nervous system (CNS) cells: astrocytes, which are heterogeneous and have many functions; oligodendrocytes, which myelinate neuronal axons; and ependymal cells, which line the fluid-filled ventricles of the brain (Raff et al. 1979). Analyzing cell suspensions prepared from developing rat brains from embryonic day eleven (E11) through to birth at approximately E21, she determined when the differentiated cells of each type first appeared. She found that the first astrocytes appeared at E15-E16, the first ependymal cells at E17-E18, and the first oligodendrocytes at around the time of birth (E21-E22). Each cell type always first appeared in very small numbers and rapidly increased over the following days. Remarkably, when she isolated cells from E10 brain and cultured them in $10 \%$ fetal calf serum (FCS), the times of first appearance of these three cell types were the same as if the cells had been left in the developing brain; moreover, when cultures were prepared from E13 brain, all three cell types first appeared 3 days earlier, just as in vivo (Abney et al. 1981). These results are as surprising today as they were when we published them more than 25 years ago, because the axial cues and morphogen gradients that play such an important part in controlling cell specification in early animal development are presumably missing in these cultures. Moreover, it seems unlikely that the sequential cell-cell interactions that are thought to help time events in development could occur normally in such cultures.

Whatever the nature of the timing mechanisms involved, the finding that they apparently could operate normally in dissociated-cell culture over a 10-day period encouraged us to study them. The complexity of the brain cell cultures, however, was daunting, and so we turned to the developing optic nerve, which is much simpler, and we focused on the timing of oligodendrocyte development.

\section{AN INTRACELLULAR TIMER IN OLIGODENDROCYTE PRECURSOR CELLS}

The optic nerve contains no neurons, although it contains the axons of retinal ganglion neurons. The main cell types in the nerve are astrocytes and oligodendrocytes, with smaller numbers of macrophages (microglia), blood vessel cells, and glial precursor cells. Whereas the astrocytes in the optic nerve develop from the neuroepithelial cells of the optic stalk (the primordium of the nerve), the oligodendrocytes develop from precursor cells that migrate into the developing nerve from the brain, beginning before birth (Small et al. 1987). The oligodendrocyte precursor cells (OPCs) divide a limited number of times before they stop and terminally differentiate into postmitotic oligodendrocytes. As in the brain, the first oligodendrocytes appear in the rat optic nerve around the day of birth, and their numbers then progressively increase over the next 6 weeks (Miller et al. 1985). Our goal was to understand why the OPCs stop dividing and differentiate when they do. This is still not known for any type of mammalian precursor cell.

As was the case in embryonic brain cell cultures, we could reconstitute the normal timing of oligodendrocyte development in dissociated cell cultures of embryonic rat optic nerve containing 10\% FCS (Raff et al. 1985). Mark Noble (then at the Institute of Neurology in London and now at Rochester Medical School) had shown that astrocytes secrete signal molecules that are required to stimulate OPCs to proliferate in culture and to prevent the premature differentiation of the OPCs into oligodencrocytes (Noble and Murray 1984). Both he and our Biology Department colleague Bill Richardson independently showed that the relevant signal molecule is platelet-derived growth factor$\alpha$ (PDGF- $\alpha$ ) (Noble et al. 1988; Richardson et al. 1988). Our three laboratories collaborated to show that PDGF can bypass the need for FCS and astrocytes and allow normal timing of oligodendrocyte development in sparse embryonic optic nerve cell cultures (Raff et al. 1988).

Sally Temple (then a Ph.D. student and now at Albany Medical School) showed that OPCs have a cell-intrinsic mechanism that helps determine when they stop dividing and differentiate (Temple and Raff 1986). She placed sin- 
gle OPCs from postnatal day 7 (P7) rat optic nerve onto monolayers of astrocytes in individual microwells and found that the isolated single cells divide a variable number of times before they differentiate, with a maximum of eight divisions. Crucially, she showed that all the progeny of an individual OPC stop dividing and differentiate at about the same time, even if the two daughter cells of an OPC are placed on astrocyte monolayers in separate microwells. These findings established that an intrinsic counting or timing mechanism is built into each OPC, and we spent much of the next 15 years trying to determine how the mechanism operates. This seemed a worthwhile effort, as it seemed likely that a similar mechanism probably operates in many types of precursor cells.

Ben Barres (then a postdoc and now at Stanford Medical School) advanced both the study and understanding of the cell-intrinsic mechanism in two important ways. First, he developed a sequential immunopanning method to purify OPCs to homogeneity from neonatal rat optic nerves (Barres et al. 1992). Second, he showed that in serum-free clonal-density cultures of purified OPCs, the intrinsic mechanism depends on thyroid hormone (TH), as well as on PDGF (Barres et al. 1994). Without PDGF, the cells prematurely stop dividing and differentiate. In the presence of PDGF but without TH, most OPCs fail to stop dividing and differentiate; if TH is added after the time when most OPCs would have differentiated had the hormone been present all along, the cells quickly stop dividing or differentiate. Ben's findings suggested that OPCs are able to count divisions or measure time in the absence of $\mathrm{TH}$ but that $\mathrm{TH}$ is required for the cells to withdraw from the cell cycle and differentiate when the intrinsic mechanism indicates it is time. Therefore, the counter or timer seems to consist of at least two functional components: (1) a counting or timing component, which depends on PDGF but not on TH and counts cell divisions or measures elapsed time, and (2) an effector component, which is regulated by TH and stops cell division and initiates differentiation when the counting or timing component indicates that it is time (Barres et al. 1994). Bögler and Noble reached a similar conclusion using a combination of PDGF and basic fibroblast growth factor-2 (FGF-2) to keep the OPCs dividing beyond their normal limit (Bögler and Noble 1994).

Why should TH regulate the intrinsic counting or timing mechanism in OPCs? Adult animals use hormones to help coordinate the behavior of their cells throughout the body, and so it is not surprising that developing animals use hormones such as TH to help coordinate the timing of development in their various organs and tissues. $\mathrm{TH}$, for example, has been shown to coordinate the onset of myelination by oligodendrocytes and Schwann cells in the central and peripheral parts, respectively, of the developing auditory nerve (Knipper et al. 1998).

Fen-Biao Gao (then a postdoc and now at the Gladstone Institute of Neurological Disease in San Francisco) used the Barres method to purify OPCs from embryonic rat optic nerves to show that in serum- and extract-free clonaldensity cultures containing PDGF and TH, the OPCs stop dividing and differentiate on the same schedule as they do in vivo (Gao et al. 1998). He also showed that, on average, OPCs purified from E18 optic nerve proliferate longer under these conditions than do OPCs purified from P7 nerve (Gao and Raff 1997), suggesting that the reason OPCs from P7 optic nerve go through a variable number of divisions before they differentiate (Temple and Raff 1986 ) is because they are at various stages of maturation. Most important, he showed that OPCs cultured at $33^{\circ} \mathrm{C}$ divide more slowly but stop dividing and differentiate earlier, after fewer divisions, than when they are cultured at $37^{\circ} \mathrm{C}$ (Gao and Raff 1997). This finding provided evidence that the cell-intrinsic mechanism does not depend on counting cell divisions but instead measures time in some other way, leading us to refer to the mechanism as an intracellular timer. But what is the other way, and why does the timer run faster at the lower temperature?

\section{SOME PROTEIN COMPONENTS OF THE INTRACELLULAR TIMER}

The first clue to the molecular nature of the intrinsic timer came from Béatrice Durand (then a postdoc and now at the Pasteur Institute in Paris). She showed that the amount of the cyclin-dependent protein kinase $(\mathrm{Cdk})$ inhibitor $\mathrm{p} 27^{\mathrm{Kip} 1}(\mathrm{p} 27)$ progressively increases in the nucleus of purified OPCs as they proliferate in the presence of PDGF and the absence of TH (Durand et al. 1997). The amount of p27 protein reaches a plateau at the time when most of the cells would have stopped dividing if TH had been present; without TH, however, the cells continue to proliferate, despite the high levels of p27. Fen-Biao Gao and Béa found that the level of p27 protein rises faster at $33^{\circ} \mathrm{C}$ than at $37^{\circ} \mathrm{C}$, suggesting that this may be one reason why the timer runs faster at the lower temperature (Gao et al. 1997). Béa then collaborated with Jim Roberts in Seattle, the head of one of the three laboratories that knocked the $p 27^{\text {Kipl }}$ gene out in mice (Fero et al. 1996; Kiyokawa et al. 1996; Nakayama et al. 1996). She showed that in cultures containing PDGF and TH, p27-deficient OPCs divide for a day or two longer than wild-type OPCs before they stop dividing and differentiate, even though the cell cycle times are indistinguishable in the mutant and wild-type cells (Durand et al. 1998). This finding suggested that p27 is one component of the timer. Moreover, Béa found that the p27-deficient cells are defective in both the timing and effector components of the timer, suggesting that p27 plays a part in both components. Jim Apperly, a Ph.D. student, showed that overexpression of p27 accelerates the timer, providing further support for a role of $\mathrm{p} 27$ in the timing process (Tokumoto et al. 2002). Yasu Tokumoto (then a postdoc and now at the Research Institute of Cell Engineering in Japan) showed that p27 mRNA levels remain constant as the protein increases in proliferating OPCs (Tokumoto et al. 2002), suggesting that the increase in $\mathrm{p} 27$ protein over time depends on posttranscriptional mechanisms, which remain to be identified.

Mice without p27 are about 30\% larger than wild-type mice and have increased cell numbers in all of their organs, as a result of increased cell proliferation rather than decreased cell death (Fero et al. 1996; Kiyokawa et al. 1996; Nakayama et al. 1996; Tokumoto et al. 2002). It therefore seems likely that $\mathrm{p} 27$ has a similar role in timing cell cycle withdrawal and differentiation in many mam- 
malian cell lineages. A homolog of p27 is present in Drosophila and Caenorhabditis elegans, and if the gene encoding it is inactivated by mutation in either organism, cells go through an extra division or two in several cell lineages (de Nooij et al. 1996; Lane et al. 1996; Hong et al. 1998). Thus, Cdk inhibitors are probably involved in stopping the cell cycle at the appropriate time during development in all animals.

The $\mathrm{p} 27$ protein, however, is only a minor component of the timer that operates in OPCs, as the timer still works in p27-deficient OPCs; it just works inaccurately. The phenotype of mice deficient in another Cdk inhibitor, $\mathrm{p} 18^{\text {Ink4c }}(\mathrm{p} 18)$, is very similar to that of $\mathrm{p} 27$-deficient mice (Franklin et al. 1998). Yasu Tokumoto found that p18 protein is expressed in OPCs and increases much like p27 as OPCs proliferate in culture, suggesting that it is also part of the timer; like p27, its increase is controlled posttranscriptionally (Tokumoto et al. 2002). Dugas, Ibrahim, and Barres recently showed that $\mathrm{p} 57^{\mathrm{Kip} 2}$ is also an important component of the timer, but in this case, $p 57^{\text {Kip } 2}$ mRNA and protein increase in parallel as OPCs proliferate, suggesting that the increase in $\mathrm{p} 57$ protein in OPCs is controlled transcriptionally (Dugas et al. 2007).

Toru Kondo (then a postdoc and now in the Riken Center for Developmental Biology in Kobe) showed that the inhibitor of differentiation protein 4 (Id4) is also a component of the timer, although it works in a manner opposite to that of p18, p27, and p57 (Kondo and Raff 2000a). Id proteins inhibit basic helix-loop-helix gene regulatory proteins that are required for the differentiation of many types of precursor cells; in this way, they inhibit differentiation and promote proliferation of the precursors. Toru found that Id4 protein decreases as purified OPCs proliferate in the presence of PDGF and the absence of TH and that Id4 mRNA and protein decrease in parallel, suggesting that a transcriptional mechanism is probably responsible for the progressive decrease in Id4 protein. He also showed that overexpression of Id4 prolongs OPC proliferation and inhibits differentiation in the presence of PDGF and TH. Toru then collaborated with Fred Sablitzky at Nottingham University to show that neural stem cells isolated from the brains of Id4-deficient mouse embryos produce oligodendrocytes prematurely in culture (Marin-Husstege et al. 2006). Taken together, these findings suggest that Id4 is another component of the timer and that its progressive decrease helps control when OPCs stop dividing and differentiate.

The OPC timer, like other intracellular timers, is still poorly understood. It is clear, however, that it is complex and depends on the progressive increase of some intracellular proteins such as p18, p27, and p57 and the progressive decrease of others such as Id4. Both transcriptional and posttranscriptional controls have roles, but how these controls operate remains to be determined.

\section{AN INTRINSIC MATURATION PROGRAM IN OPCS}

The intracellular timer that helps control when OPCs withdraw from the cell cycle and differentiate seems to be only one part of a much more complex cell-intrinsic tim- ing mechanism that changes many of the properties of OPCs over time.

Charles ffrench-Constant (then a medically trained Ph.D. student and now at Edinburgh University) found that there are small numbers of OPCs in cell suspensions prepared from adult rat optic nerves (ffrench-Constant and Raff 1986), suggesting that OPCs are present in the optic nerve throughout postnatal life. Mark Noble and his colleagues independently found these adult OPCs and characterized them in more detail (Wolswijk and Noble 1989). Julia Burne (a technician turned Ph.D. student) collaborated with Barbara Fulton in the Anatomy Department at University College London to visualize OPCs in the rat optic nerve at different times in development. They found that the cells become progressively more complex in morphology with age (Fulton et al. 1992), but it is not clear whether these changes reflect changes in the cells' environment with age, an intrinsic maturation program operating within the cells themselves, or both.

Fen-Biao Gao provided strong evidence that perinatal OPCs, at least, have an intrinsic developmental program that changes many aspects of the cell over time (Gao and Raff 1997). He first compared the properties of purified E18 OPCs to those of purified P7 OPCs (which are 10 days older) using time-lapse video recording of individual clones in culture. He found that in serum-free cultures containing PDGF but not TH, the embryonic OPCs have a simpler morphology than the P7 OPCs and divide and migrate faster; moreover, in the presence of PDGF and $\mathrm{TH}$, the embryonic cells divide more times before differentiating than do the P7 cells. Remarkably, when he cultured purified E18 OPCs in PDGF without TH for 10 days (so that they were now the same age as freshly isolated P7 OPCs), he found that the embryonic cells had acquired all the properties of the P7 cells, indicating that developing OPCs have an intrinsic maturation program.

Dean Tang (then a postdoc and now at M.D. Anderson Cancer Center) and Yasu Tokumoto showed that purified P7 rat OPCs can proliferate in serum-free culture for more than 1 year in PDGF without TH. After many months in culture, Dean found that the OPCs start to express the glycolipid galactocerebroside (Tang et al. 2000), which we originally believed was expressed in the CNS only by oligodendrocytes and myelin (Raff et al. 1978). The galactocerebroside-expressing OPCs continue to proliferate and do not express other oligodendrocyte or myelin markers. The expression of galactocerebroside is unlikely to be a culture artifact, as Ben Barres and his colleagues showed earlier that OPCs in the rat optic nerve start to express galactocerebroside after months in vivo (Shi et al. 1998). Is it possible that the intrinsic maturation program in OPCs continues to change the cells for months? This would be remarkable and would raise the question of how such an extended program could work.

It is important to emphasize that the developmental programs and timers described here in OPCs are not set in stone. As already mentioned, for example, most OPCs ignore the timer that helps determine when they stop dividing and differentiate if $\mathrm{TH}$ is omitted from the cul- 
ture medium (Barres et al. 1994). Moreover, Toru Kondo found that OPCs are not irreversibly committed to becoming oligodendrocytes or even glial cells: Transient exposure of purified OPCs in culture to bone morphogenetic protein 4 (BMP4), followed by FGF-2, rapidly reprograms the cells to become more like multipotential CNS neural stem cells, which can now produce both neurons and glia (Kondo and Raff 2000b). Remarkably, a 2-day treatment with BMP4 is enough to induce the transcription of a variety of genes that are normally expressed in neural stem cells but not in untreated OPCs (Kondo and Raff 2004).

\section{A PUTATIVE TIMER PROTEIN IN SILKWORM}

One of the most interesting intracellular timers ever reported seems to have received little if any attention, which is surprising, given its uniqueness and potential implications. It concerns the timing of diapause in the silkworm Bombyx mori, which Professor Hidenori Kai of Tottori University in Japan has been studying for more than 30 years. I have had nothing to do with this work, but I discuss it here because so few cell and developmental biologists seem to know about it.

In response to particular environmental conditions, many developing insects enter diapause, a period of developmental arrest (Denlinger 2002). In summer temperatures and long day lengths, for example, the developing eggs of $B$. mori are programmed by a hormone to enter diapause several days after the eggs are laid. Subsequent exposure to cold $\left(\sim 5^{\circ} \mathrm{C}\right)$ triggers the eggs to complete diapause, a process that takes 2 weeks if the eggs are cooled 2 days after they are laid and maintained at the low temperature for the entire period. Kai originally reported that an enzyme activity, assayed as an esterase, turns on after 2 weeks at $5^{\circ} \mathrm{C}$ and then turns off again within 24 hours (Kai and Nishi 1976). Remarkably, he later found that the same thing happens when he cooled an extract of the eggs in a test tube for 2 weeks (Kai et al. 1987). Even more remarkably, he subsequently showed that a purified preparation of the enzyme (now assayed as an ATPase) behaves similarly: The enzyme becomes active after 2 weeks at $5{ }^{\circ} \mathrm{C}$ and then rapidly inactivates again (Kai et al. 1995). Kai calls the protein TIME (time-interval measuring enzyme), as it seems to measure the duration of the cold-induced diapause completion process (called diapause development). After completion, if the eggs are warmed, embryo development restarts, leading to hatching after about 12 days.

Two other properties of TIME are equally fascinating. First, the enzyme cannot be reactivated after it has turned on in the cold and turned off again, unless it is treated with a denaturant (6 $\mathrm{M}$ guanidine- $\mathrm{HCl})$, in which case it responds to cooling in the same way as it does in freshly isolated extracts of diapause eggs (Kai et al. 1995). Second, TIME is physically associated in the developing egg with a small peptide called PIN (peptidyl inhibitory needle), which rapidly dissociates from TIME at $5^{\circ} \mathrm{C}$, allowing the enzyme to start measuring time ( $\mathrm{Ti}$ et al. 2005). The time period that PIN remains associated with TIME determines how long diapause development takes after cooling ( Ti et al. 2006). It seems that at warm (summer) temperatures, PIN restructures TIME into a timekeeping conformation and does so progressively over days.

The amino acid sequences of TIME and PIN have been determined (Isobe et al. 2006). TIME contains 156 amino acids and PIN 38 amino acids, and both contain copper ions. TIME does not contain an obvious ATPase domain, but it does contain a functional $\mathrm{Cu}, \mathrm{Zn}$ superoxide dismutase domain, the activity of which does not vary during diapause development. How TIME measures time remains a mystery, but it presumably involves a series of conformational changes that occur over many days at $5^{\circ} \mathrm{C}$.

\section{CONCLUSIONS}

It is unlikely that circadian oscillators play an important part in timing events in animal development. Nonetheless, the intracellular programs that change developing animal cells over time and help control the timing of developmental events should be of some interest to biologists who study timing mechanisms in cells. They surely deserve more attention than they have received so far.

\section{ACKNOWLEDGMENTS}

I am extremely grateful to the postdocs, students, and associates mentioned, as well as those lab members not mentioned because their work fell outside the subject of this review; it was a privilege having them as friends and colleagues. I am also grateful to the Medical Research Council for providing my salary and research support for 31 years.

\section{REFERENCES}

Abney E.R., Bartlett P.P., and Raff M.C. 1981. Astrocytes, ependymal cells, and oligodendrocytes develop on schedule in dissociated cell cultures of embryonic rat brain. Dev. Biol. 83: 301 .

Barres B.A., Lazar M.A., and Raff M.C. 1994. A novel role for thyroid hormone, glucocorticoids and retinoic acid in timing oligodendrocyte development. Development 120: 1097.

Barres B.A., Hart I.K., Coles H.S., Burne J.F., Voyvodic J.T., Richardson W.D., and Raff M.C. 1992. Cell death and control of cell survival in the oligodendrocyte lineage. Cell 70: 31.

Bögler O. and Noble M. 1994. Measurement of time in oligodendrocyte-type-2 astrocyte $(\mathrm{O}-2 \mathrm{~A})$ progenitors is a cellular process distinct from differentiation or division. Dev. Biol. 162: 525.

de Nooij J.C., Letendre M.A., and Hariharan I.K. 1996. A cyclin-dependent kinase inhibitor, Dacapo, is necessary for timely exit from the cell cycle during Drosophila embryogenesis. Cell 87: 1237.

Denlinger D.L. 2002. Regulation of diapause. Annu. Rev. Entomol. 47: 93.

Dugas J.C., Ibrahim A., and Barres B.A. 2007. A crucial role for p57(Kip2) in the intracellular timer that controls oligodendrocyte differentiation. J. Neurosci. 27: 6185.

Durand B., Gao F.B., and Raff M. 1997. Accumulation of the cyclin-dependent kinase inhibitor $\mathrm{p} 27 / \mathrm{Kip} 1$ and the timing of oligodendrocyte differentiation. EMBO J. 16: 306.

Durand B., Fero M.L., Roberts J.M., and Raff M.C. 1998. p27Kip1 alters the response of cells to mitogen and is part of a cell-intrinsic timer that arrests the cell cycle and initiates differentiation. Curr. Biol. 8: 431. 
Fero M.L., Rivkin M., Tasch M., Porter P., Carow C.E., Firpo E., Polyak K., Tsai L.H., Broudy V., Perlmutter R.M., Kaushansky K., and Roberts J.M. 1996. A syndrome of multiorgan hyperplasia with features of gigantism, tumorigenesis, and female sterility in p27(Kip1)-deficient mice. Cell 85: 733.

ffrench-Constant C. and Raff M.C. 1986. Proliferating bipotential glial progenitor cells in adult rat optic nerve. Nature 319: 499.

Franklin D.S., Godfrey V.L., Lee H., Kovalev G.I., Schoonhoven R., Chen-Kiang S., Su L., and Xiong Y. 1998. CDK inhibitors p18(INK4c) and p27(Kip1) mediate two separate pathways to collaboratively suppress pituitary tumorigenesis. Genes Dev. 12: 2899.

Fulton B.P., Burne J.F., and Raff M.C. 1992. Visualization of O$2 \mathrm{~A}$ progenitor cells in developing and adult rat optic nerve by quisqualate-stimulated cobalt uptake. J. Neurosci. 12: 4816.

Gao F.B. and Raff M. 1997. Cell size control and a cell-intrinsic maturation program in proliferating oligodendrocyte precursor cells. J. Cell Biol. 138: 1367.

Gao F.B., Apperly J., and Raff M. 1998. Cell-intrinsic timers and thyroid hormone regulate the probability of cell-cycle withdrawal and differentiation of oligodendrocyte precursor cells. Dev. Biol. 197: 54.

Gao F.B., Durand B., and Raff M. 1997. Oligodendrocyte precursor cells count time but not cell divisions before differentiation. Curr. Biol. 7: 152.

Hong Y., Roy R., and Ambros V. 1998. Developmental regulation of a cyclin-dependent kinase inhibitor controls postembryonic cell cycle progression in Caenorhabditis elegans. Development 125: 3585.

Isobe M., Kai H., Kurahashi T., Suwan S., PitchayawasinThapphasaraphong S., Franz T., Tani N., Higashi K., and Nishida H. 2006. The molecular mechanism of the termination of insect diapause. 1. A timer protein, TIME-EA4, in the diapause eggs of the silkworm Bombyx mori is a metallo-glycoprotein. Chembiochem. 7: 1590.

Kai H. and Nishi K. 1976. Diapause development in Bombyx eggs in relation to "esterase A" activity. J. Insect Physiol. 22: 1315 .

Kai H., Kawai T., and Kawai Y. 1987. A time-interval activation of esterase A4 by cold: Relation to the termination of embryonic diapause in the silkworm, Bombyx mori. Insect Biochem. 17: 367.

Kai H., Kotani Y., Miao Y., and Azuma M. 1995. Time interval measuring enzyme for resumption of embryonic development in the silkworm, Bombyx mori. J. Insect Physiol. 41: 905.

Kiyokawa H., Kineman R.D., Manova-Todorova K.O., Soares V.C., Hoffman E.S., Ono M., Khanam D., Hayday A.C., Frohman L.A., and Koff A. 1996. Enhanced growth of mice lacking the cyclin-dependent kinase inhibitor function of p27(Kip1). Cell 85: 721.

Knipper M., Bandtlow C., Gestwa L., Kopschall I., Rohbock K., Wiechers B., Zenner H.P., and Zimmermann U. 1998. Thyroid hormone affects Schwann cell and oligodendrocyte gene expression at the glial transition zone of the VIIIth nerve prior to cochlea function. Development 125: 3709 .

Kondo T. and Raff M. 2000a. The Id4 HLH protein and the timing of oligodendrocyte differentiation. EMBO J. 19: 1998.

. 2000b. Oligodendrocyte precursor cells reprogrammed to become multipotential CNS stem cells. Science 289: 1754 .

-2004. Chromatin remodeling and histone modification in the conversion of oligodendrocyte precursors to neural stem cells. Genes Dev. 18: 2963.

Lane M.E., Sauer K., Wallace K., Jan Y.N., Lehner C.F., and Vaessin H. 1996. Dacapo, a cyclin-dependent kinase inhibitor, stops cell proliferation during Drosophila development. Cell 87: 1225.
Marin-Husstege M., He Y., Li J., Kondo T., Sablitzky F., and Casaccia-Bonnefil P. 2006. Multiple roles of Id4 in developmental myelination: Predicted outcomes and unexpected findings. Glia 54: 285.

Miller R.H., David S., Patel R., Abney E.R., and Raff M.C. 1985. A quantitative immunohistochemical study of macroglial cell development in the rat optic nerve: In vivo evidence for two distinct astrocyte lineages. Dev. Biol. 111: 35 .

Nakayama K., Ishida N., Shirane M., Inomata A., Inoue T., Shishido N., Horii I., and Loh D.Y. 1996. Mice lacking p27(Kip1) display increased body size, multiple organ hyperplasia, retinal dysplasia, and pituitary tumors. Cell 85: 707 .

Noble M. and Murray K. 1984. Purified astrocytes promote the in vitro division of a bipotential glial progenitor cell. $E M B O$ J. 3: 2243.

Noble M., Murray K., Stroobant P., Waterfield M.D., and Riddle P. 1988. Platelet-derived growth factor promotes division and motility and inhibits premature differentiation of the oligodendrocyte/type-2 astrocyte progenitor cell. Nature 333: 560 .

Raff M.C., Abney E.R., and Fok-Seang J. 1985. Reconstitution of a developmental clock in vitro: A critical role for astrocytes in the timing of oligodendrocyte differentiation. Cell 42: 61.

Raff M.C., Lillien L.E., Richardson W.D., Burne J.F., and Noble M.D. 1988. Platelet-derived growth factor from astrocytes drives the clock that times oligodendrocyte development in culture. Nature 333: 562

Raff M.C., Fields K.L., Hakomori S.I., Mirsky R., Pruss R.M., and Winter J. 1979. Cell-type-specific markers for distinguishing and studying neurons and the major classes of glial cells in culture. Brain Res. 174: 283.

Raff M.C., Mirsky R., Fields K.L., Lisak R.P., Dorfman S.H., Silberberg D.H., Gregson N.A., Leibowitz S., and Kennedy M.C. 1978. Galactocerebroside is a specific cell-surface antigenic marker for oligodendrocytes in culture. Nature 274: 813.

Richardson W.D., Pringle N., Mosley M.J., Westermark B., and Dubois-Dalcq M. 1988. A role for platelet-derived growth factor in normal gliogenesis in the central nervous system. Cell 53: 309.

Shi J., Marinovich A., and Barres B.A. 1998. Purification and characterization of adult oligodendrocyte precursor cells from the rat optic nerve. J. Neurosci. 18: 4627.

Small R.K., Riddle P., and Noble M. 1987. Evidence for migration of oligodendrocyte-type- 2 astrocyte progenitor cells into the developing rat optic nerve. Nature 328: 155 .

Tang D.G., Tokumoto Y.M., and Raff M.C. 2000. Long-term culture of purified postnatal oligodendrocyte precursor cells. Evidence for an intrinsic maturation program that plays out over months. J. Cell Biol. 148: 971.

Temple S. and Raff M.C. 1986. Clonal analysis of oligodendrocyte development in culture: Evidence for a developmental clock that counts cell divisions. Cell 44: 773.

Ti X., Tani N., Isobe M., and Kai H. 2006. Time-measurementregulating peptide PIN may alter a timer conformation of Time Interval Measuring Enzyme (TIME). J. Insect Physiol. 52: 461 .

Ti X., Tuzuki N., Tani N., Isobe M., and Kai H. 2005. The peptide PIN changes the timing of transitory burst activation of timer-ATPase TIME in accordance with diapause development in eggs of the silkworm, Bombyx mori. J. Insect Physiol. 51: 1025 .

Tokumoto Y.M., Apperly J.A., Gao F.B., and Raff M.C. 2002. Posttranscriptional regulation of $\mathrm{p} 18$ and $\mathrm{p} 27 \mathrm{Cdk}$ inhibitor proteins and the timing of oligodendrocyte differentiation. Dev. Biol. 245: 224

Wolswijk G. and Noble M. 1989. Identification of an adult-specific glial progenitor cell. Development 105: 387. 


\section{$8_{\mathrm{CSH}}^{\infty} \mathrm{C}$ Cold Spring Harbor Symposia SYMPOSIA on Quantitative Biology}

\section{Intracellular Developmental Timers}

M. Raff

Cold Spring Harb Symp Quant Biol 2007 72: 431-435

Access the most recent version at doi:10.1101/sqb.2007.72.007

References This article cites 45 articles, 14 of which can be accessed free at: http://symposium.cshlp.org/content/72/431.full.html\#ref-list-1

\section{License}

Email Alerting

Receive free email alerts when new articles cite this article - sign up in the box at the Service top right corner of the article or click here.

To subscribe to Cold Spring Harbor Symposia on Quantitative Biology go to: http://symposium.cshlp.org/subscriptions 